\title{
Análises multivariadas em genótipos de feijão roxo no ecótono Cerrado-Pantanal
}

\author{
Multivariate analyzes in red bean genotypes in the Cerrado-Pantanal ecotone \\ Análisis multivariados en genotipos de frijol rojo en el ecotono Cerrado-Pantanal
}

Recebido: 22/11/2021 | Revisado: 02/12/2021 | Aceito: 10/12/2021 | Publicado: 17/12/2021

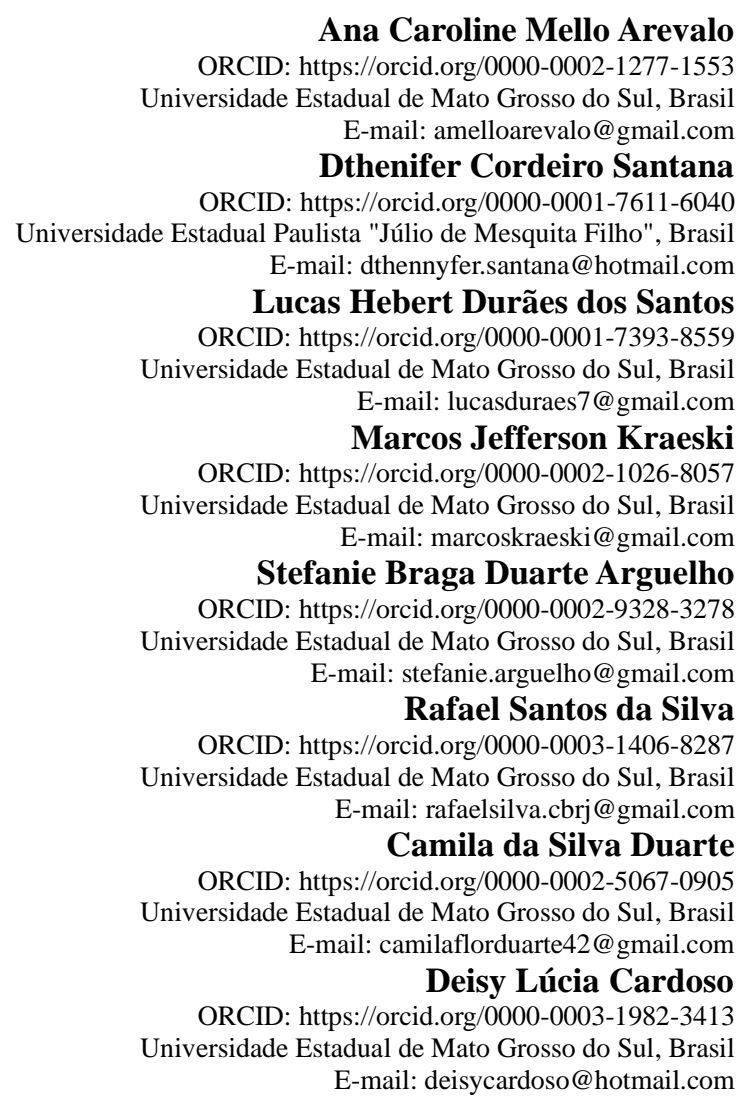

\section{Resumo}

O feijoeiro-comum (Phaseolus vulgaris, L.) é a espécie mais cultivada entre as demais do gênero Phaseolus. O tipo roxo está entre os grupos comerciais de feijão-comum cultivados no Brasil. O objetivo deste trabalho foi avaliar o desempenho agronômico de dez genótipos de feijão roxo na região do ecótono Cerrado-Pantanal. O experimento foi realizado na Universidade Estadual de Mato Grosso do Sul, no município de Aquidauana. O delineamento adotado foi em blocos casualizados com três repetições. Os dez genótipos utilizados fazem parte da rede nacional de ensaios de Valor de Cultivo e Uso (VCU) desenvolvidos pela Embrapa - Centro Nacional de Pesquisa de Arroz e Feijão. Foram avaliados a altura de inserção da primeira vagem (AIV); número de vagens por planta (NVP); número de grãos por vagem (NGV); massa de cem grãos (MCG); e produtividade (PROD). Quanto as análises estatísticas, foram processadas análises de variância multivariada, variáveis canônicas e análise de agrupamento, utilizando o software Rbio. Nas análises de variáveis canônicas observa-se que as duas primeiras variáveis explicam mais de $80 \%$ da variação total contida no conjunto de dados originais. O dendrograma dividiu os genótipos de feijão roxo em 4 grupos, sendo a produtividade a variável de maior influência, consequentemente, de mais intensa contribuição para a separação dos grupos, seguido da massa de cem grãos. Os genótipos CNFRx 16353, CNFRx 16340 e CNFR 16932, foram os que apresentaram as maiores médias para a variável produtividade.

Palavras-chave: Desempenho agronômico de feijoeiro; Phaseolus vulgaris, L.; Variáveis canônicas.

\section{Abstract}

Common bean (Phaseolus vulgaris, L.) is the most cultivated species among the other species of the genus Phaseolus. The roxo type is among the commercial groups of common bean cultivated in Brazil. The objective of this work was to evaluate the agronomic performance of ten genotypes of roxo beans in the cerrado-pantanal ecótono region. The experiment was carried out at the State University of Mato Grosso do Sul, in the municipality of Aquidauana. The 
design adopted was in randomized blocks with three replications. The ten genotypes used are part of the national network of Cultivation and Use Value (VCU) tests developed by Embrapa - National Rice and Bean Research Center. The insertion height of the first pod (AIV) was evaluated; number of pods per plant (NVP); number of grains per pod $(\mathrm{NGV})$; mass of one hundred grains (MCG); productivity (PROD). As for the statistical analyses, multivariate variance analyses, canonical variables and cluster analysis were processed using the Rbio software. In the analysis of canonical variables, it is observed that the first two variables explain more than $80 \%$ of the total variation contained in the original data set. The dendrogram divided the roxo bean genotypes into 4 groups, and productivity was the variable with the greatest influence, consequently, of the most intense contribution to the separation of the groups, followed by the mass of one hundred grains. The genotypes CNFRx 16353, CNFRx 16340 and CNFR 16932 presented the highest averages for the productivity variable.

Keywords: Agronomic performance of common bean; Phaseolus vulgaris, L.; Canonical variables.

\section{Resumen}

El frijol común (Phaseolus vulgaris, L.) es la especie más cultivada entre las otras especies del género Phaseolus. El tipo roxo se encuentra entre los grupos comerciales de frijol común cultivado en Brasil. El objetivo de este trabajo fue evaluar el desempeño agronómico de diez genotipos de frijol roxo en la región del ecótono cerrado-pantanal. El experimento se llevó a cabo en la Universidad Estatal de Mato Grosso do Sul, en el municipio de Aquidauana. El diseño adoptado fue en bloques aleatorios con tres replicaciones. Los diez genotipos utilizados forman parte de la red nacional de pruebas de Cultivo y Valor de Uso (VCU) desarrolladas por Embrapa - Centro Nacional de Investigación de Arroz y Frijol. Se evaluó la altura de inserción de la primera vaina (AIV); número de vainas por planta (NVP); número de granos por vaina (GNV); masa de cien granos (MCG); productividad (PROD). En cuanto a los análisis estadísticos, los análisis de varianza multivariante, las variables canónicas y el análisis de conglomerados se procesaron utilizando el software Rbio. En el análisis de variables canónicas, se observa que las dos primeras variables explican más del $80 \%$ de la variación total contenida en el conjunto de datos original. El dendrograma dividió los genotipos de frijol roxo en 4 grupos, y la productividad fue la variable con mayor influencia, en consecuencia, de la contribución más intensa a la separación de los grupos, seguida de la masa de cien granos. Los genotipos CNFRx 16353, CNFRx 16340 y CNFR 16932 presentaron los promedios más altos para la variable de productividad.

Palabras clave: Rendimiento agronómico del frijol común; Phaseolus vulgaris, L.; Variables canónicas.

\section{Introdução}

O Brasil se destaca como maior produtor e consumidor mundial do feijão-comum (Phaseolus vulgaris L.), também conhecido como feijoeiro, é a espécie mais cultivada entre as demais do gênero Phaseolus (Fao, 2019).

Consumido em todas as regiões do País, a cultura apresenta grande importância socioeconômica, estando presente na mesa dos brasileiros, sendo fonte de proteínas, ferro e carboidratos. Além disso, pode ser utilizado para a alimentação animal (Moraes \& Menelau, 2017). No entanto, nos últimos anos, sua comercialização tem apresentado demandas diferentes das tradicionais do tipo carioca, onde novos consumidores tem realizado buscas por "grãos de feijão especiais" para consumo (Chiorato et al. 2018).

O grupo dos feijões conhecidos como de grãos especiais são aqueles que possuem particularidades quanto a cor do tegumento, forma e tamanho dos grãos, bem como potencial nutricional e culinários diferentes, como exemplo temos o tipo roxo, rosinha, rajado, entre outros (Carbonell et al., 2020).

De acordo com Schmitz et al. (2020) estes grãos especiais geralmente são cultivados por pequenos produtores e as informações sobre suas características morfológicas, fenológicas, agronômicas e nutricionais muitas vezes são escassas e, devido à falta de cultivares adaptados e com alta produtividade de grãos, a produção ainda é incipiente no Brasil.

Assim, os programas de melhoramento têm buscado desenvolver novas cultivares que promovam a variabilidade dos tipos de feijão comum para consumo no Brasil, agregando valor no mercado nacional para esses grãos especiais e permitindo também a abertura para a exportação (Carbonell et al., 2020).

Dada a importância de desenvolvimento de novas cultivares de grãos especiais, como do tipo roxo, por meio da rede nacional de ensaios de Valor de Cultivo e Uso (VCU) desenvolvidos pela Embrapa - Centro Nacional de Pesquisa de Arroz e Feijão, o objetivo do presente trabalho foi avaliar o desempenho agronômico de dez genótipos de feijão roxo na região do 
ecótono Cerrado-Pantanal, utilizando as análises canônicas e de agrupamentos para obtenção dos resultados estatísticos.

\section{Metodologia}

O trabalho foi conduzido na Universidade Estadual de Mato Grosso do Sul - Unidade Universitária de Aquidauana,

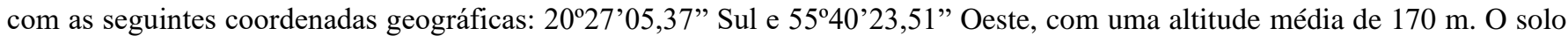
do local foi classificado, de acordo com Schiavo et al. (2010) como Argissolo Vermelho-Amarelo distrófico de textura arenosa e o clima, segundo a classificação de KÖPPEN, é Aw, definido como tropical quente sub-úmido, com estação chuvosa no verão e seca no inverno, possuindo uma precipitação média anual de $1200 \mathrm{~mm}$.

Foram avaliados dez genótipos de feijão roxo, o experimento foi conduzido em blocos casualizados com três repetições. As parcelas foram constituídas com quatro linhas de quatro metros de comprimento, com espaçamento de $0,5 \mathrm{~m}$ entre linhas com 12 plantas por metro linear. A área útil constitui-se das duas fileiras centrais.

$\mathrm{Na}$ área onde foi implantado o experimento, inicialmente foi realizado o preparo e incorporação do solo através de gradagem e abertura de sulcos, sendo realizada adubação de base, na dose de $270 \mathrm{~kg} \mathrm{ha}^{-1}$ do formulado 4-20-20 e realizado a incorporação deste adubo de forma manual. Em seguida foi realizada a semeadura, de forma manual, dos genótipos buscando obter 12 sementes por metro linear na profundidade 3-5 $\mathrm{cm}$. Dois dias após a semeadura foi realizada a irrigação da área utilizando aspersores do tipo convencional, com lâmina d'água de $10 \mathrm{~mm}$ visando proporcionar umidade suficiente para a emergência das plântulas. Quando as plantas estavam no estágio V3 (abertura da primeira folha trifoliada), foi realizado controle das plantas invasoras com auxílio de enxadas.

No estágio V4 (terceira folha trifoliada totalmente aberta) foi realizado uma adubação de cobertura com a dose de $60 \mathrm{~kg} \mathrm{ha}^{-1}$ de ureia, e realizada irrigação com lâmina de $10 \mathrm{~mm}$ para incorporação do adubo ao solo e consequentemente menores perdas por volatilização do adubo. Entre os estágios R5 (início do florescimento) e R8 (enchimento de grão), períodos onde a cultura mais necessita de maior volume de água disponível, foram realizadas diversas irrigações com lâminas de $10 \mathrm{~mm}$.

Quando as plantas entraram no estádio R9 (estágio de maturação), com o experimento ainda em campo, foram colhidas 8 plantas de cada parcela e realizado as seguintes avaliações: Altura de inserção da primeira vagem (AIV): expressa em centímetros $(\mathrm{cm})$, medidos com auxílio de uma régua graduada, correspondendo a distância entre colo da planta à inserção da primeira vagem; e Número de vagens por planta (NVP): determinado pela contagem de todas as vagens das oito plantas coletadas que já possuíam grãos, dispensando assim, os canivetes.

Posteriormente, foi realizado a colheita de todas as plantas de cada parcela de forma manual, sendo empilhadas, para que ocorresse a secagem das vagens e após realizado a debulha (bateção) das plantas para separar os grãos das vagens. E realizado as avaliações das seguintes características: Número de grãos por vagem (NGV): determinado pela contagem do número de grãos em cada vagem, de uma amostra de 24 vagens em cada parcela, obtendo-se o número médio de grãos por vagem; Massa de cem grãos (MCG): Expressa em gramas, obtido pela pesagem, em balança semi analítica, de uma amostra em cem grãos de cada parcela; e Produtividade (PROD): expressa em kg ha ${ }^{-1}$ obtida pela pesagem de todos os grãos da parcela e transformados em $\mathrm{kg} \mathrm{ha}^{-1}$.

Os tratamentos tiveram as suas médias agrupadas pelo teste de Scott \& Knott a 5\% de probabilidade, utilizando o software Genes (Cruz, 2013). Em seguida, realizou-se análise de variância multivariada, para se observar a significância das variáveis, utilizando o software Rbio (Bhering, 2017) as quais foram todas significativas, sendo utilizadas na análise de agrupamento e variáveis canônicas, realizadas no software Rbio (Bhering, 2017).

Para a análise de agrupamento foi utilizado a distância Euclidiana média (Cruz et al., 2014), como medida de dissimilaridade e, na delimitação dos grupos, o método hierárquico de Ward e o corte do dendrograma realizado pelo critério 
de Mojema (1977) com k=1,5. A análise de variáveis canônicas foi realizada pela dispersão dos escores em gráfico bidimensional, com os eixos representados pelas primeiras variáveis canônicas que explicaram um mínimo de $80 \%$ da variação dos dados avaliados para essa análise foram adotados procedimentos preconizados por Cruz et al. (2014).

\section{Resultados e Discussão}

Os resultados obtidos mediante a análise de variância através do teste $\mathrm{F}$ encontram-se na Tabela 1. Nota-se que estatisticamente apenas duas características apresentaram diferença significativa, que foram massa de 100 grãos (MCG) e produtividade (PROD), ambas a 1\% de probabilidade. Enquanto que para outras características (AIV, NVP e NGV) não houve uma diferença significativa.

Tabela 1. Resumo das análises de variâncias de variáveis estruturais, componentes primários de produção e produtividade de grãos de dez genótipos de feijão roxo cultivados na região do ecótono Cerrado-Pantanal.

\begin{tabular}{|c|c|c|c|c|c|c|}
\hline \multirow{2}{*}{ F.V. } & \multirow{2}{*}{ G.L. } & \multicolumn{5}{|c|}{ Quadrado Médio } \\
\hline & & AIV & NVP & NGV & MCG & PROD \\
\hline Blocos & 2 & 2,43 & 33,95 & 2,27 & 0,60 & 195.074 \\
\hline Tratamentos & 9 & $6,39^{\text {ns }}$ & $7,75^{\mathrm{ns}}$ & $0,59^{\mathrm{ns}}$ & $12,19^{* *}$ & $1.717 .482,17^{\text {*** }}$ \\
\hline Resíduos & 18 & 5,20 & 5,52 & 0,47 & 2,53 & $58.435,91$ \\
\hline $\mathrm{CV}(\%)$ & & 15,31 & 11,45 & 15,06 & 6,06 & 11,90 \\
\hline Média & & 14,89 & 20,52 & 4,53 & 26,27 & $2.030,99$ \\
\hline
\end{tabular}

CV. = coeficiente de variação; Altura de inserção da primeira vagem (AIV, $\mathrm{cm}$ ); número de vagens por planta (NVP); número de grãos por vagem (NGV); massa de cem grãos (MCG, grama); produtividade de grãos $\left(\mathrm{PROD}, \mathrm{kg} \mathrm{ha}^{-1}\right){ }^{\text {ns }}=$ não significativo; $* *=$ significativo a $1 \%$ de probabilidade pelo teste de Scott \& Knott. Fonte: Autores.

Ponce (2017) e Melo (2017), não observaram diferença significativa para a variável NVP. Todavia, mesmo não havendo diferença significativa entre os genótipos, os autores observaram diferença de até $30 \%$ de acréscimo para a variável NVP. Esta variável que, juntamente com as variáveis número de grãos por vagem e a massa de grãos estão ligadas aos resultados de produtividade obtidos em um genótipo, de modo que essas variáveis são consideradas importantes na seleção de genótipos produtivos (Schmitz et al., 2020). Uma vez que, se considerarmos um genótipo apresente maior número de vagens por planta, maior número de grãos por vagens e maior massa de cem grãos que outro genótipo, nas mesmas condições ambientais, consequentemente este genótipo pode ser considerado superior.

Analisando as características MCG e PROD que apresentaram diferença significativa entres os genótipos (Tabela 2), nota-se que para MCG houve diferença significativa, separando os genótipos em dois grupos, onde cinco genótipos se destacaram e apresentando valores acima da média: BRSCNFRx15595, CNFRx16353, CNFRx 16340, CNFRX 16360 e CNFRx 16352.

Ao analisar a característica produtividade (PROD), nota-se que houve diferença significativa entre os genótipos, em que quatro deles apresentaram médias superiores aos demais, sendo CNFRx 16353, CNFRx 16340 e CNFR 16932, os que apresentaram as maiores médias. 
Tabela 2. Médias massa de cem grãos (MCG, g) e produtividade (PROD, $\mathrm{kg} \mathrm{ha}^{-1}$ ) de dez genótipos de feijão roxo cultivados na região do ecótono Cerrado-Pantanal.

\begin{tabular}{lcc}
\hline Genótipos & MCG & PROD \\
\hline BRSMG TESOURO & $25,96 \mathrm{~b}$ & $1.620,53 \mathrm{~b}$ \\
CNFR 17014 & $24,86 \mathrm{~b}$ & $1.914 .40 \mathrm{~b}$ \\
CNFR 16932 & $25,39 \mathrm{~b}$ & $2.371,89 \mathrm{a}$ \\
CNFR 16997 & $22,82 \mathrm{~b}$ & $887,60 \mathrm{c}$ \\
CNFR 16998 & $24,21 \mathrm{~b}$ & $1.746 .36 \mathrm{~b}$ \\
CNFRx 16340 & $27,42 \mathrm{a}$ & $2.451,36 \mathrm{a}$ \\
CNFRx 16353 & $27,84 \mathrm{a}$ & $2.935,13 \mathrm{a}$ \\
CNFRx 16352 & $26,88 \mathrm{a}$ & $963,77 \mathrm{c}$ \\
BRSCNFRx15595 & $29,67 \mathrm{a}$ & $2.260,32 \mathrm{a}$ \\
CNFRX 16360 & $27,36 \mathrm{a}$ & $2.071,99 \mathrm{~b}$ \\
\hline
\end{tabular}

*Médias seguidas da mesma letra não diferem entre si pelo teste de Scott Knott à 5\%. Fonte: Autores.

$\mathrm{Na}$ análise canônica (Figura 1) as duas primeiras variáveis, referentes aos cinco caracteres agronômicos avaliados, viabilizaram a construção de uma dispersão gráfica, pelo fato de explicarem mais de $80 \%$ da variação total contida no conjunto de dados originais.

Figura 1. Análise de variáveis canônicas para dez genótipos de feijão roxo em Aquidauana, safra de inverno.

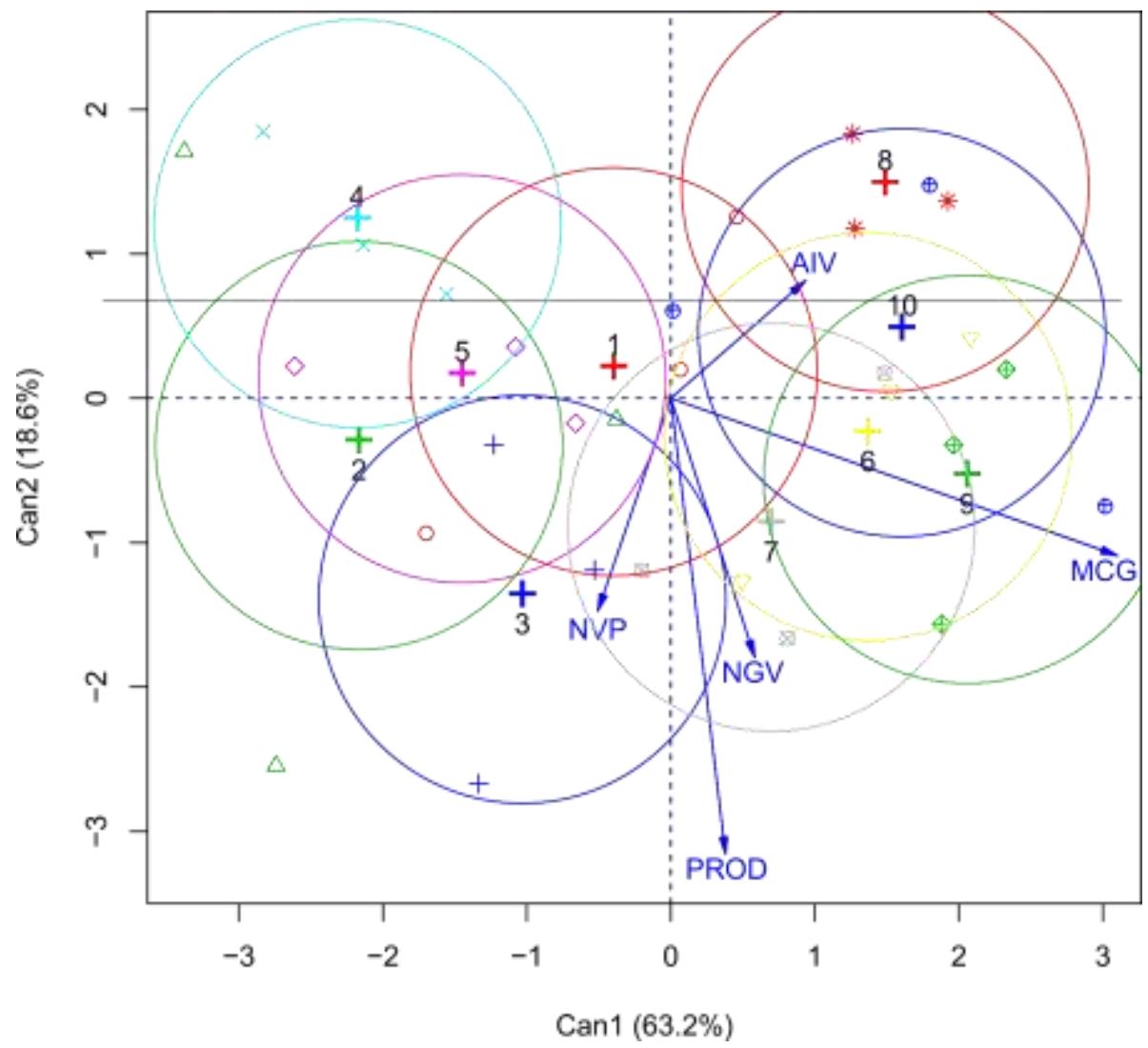

Genótipos: ${ }^{1}$ BRSMG TESOURO, ${ }^{2} \mathrm{CNFR} \quad 17014,{ }^{3} \mathrm{CNFR}$ 16932, ${ }^{4} \mathrm{CNFR} \quad 16997,{ }^{5} \mathrm{CNFR} \quad 16998,{ }^{6} \mathrm{CNFRx} \quad 16340,{ }^{7} \mathrm{CNFRx} \quad 16353,{ }^{8} \mathrm{CNFRx} \quad 16352$, ${ }^{9}$ BRSCNFRx15595 e ${ }^{10} \mathrm{CNFRX} 16360$; Variáveis altura de inserção da primeira vagem (AIV, cm), número de vagens por planta (NVP), número de grãos por vagem (NGV), massa de cem grãos (MCG, gramas), produtividade de grãos (PROD, $\mathrm{kg} \mathrm{ha}^{-1}$ ). Fonte: Autores.

Nota-se que os genótipos CNFRx 16352 e CNFRX 16360 (8 e 10 respectivamente) tiveram maior relação com a variável AIV.

Para a variável NVP os genótipos que obtiveram maior relação foram os CNFR 17014 e CNFR 16932 (2 e 3, respectivamente). Já os genótipos CNFRx 16340, CNFRx 16353 e BRSCNFRx15595 (6, 7 e 9 respectivamente) tiveram 
destaque para as variáveis NGV, MCG e principalmente para PROD.

Sulzbacher et al. (2017) obtiveram resultados similares, onde as duas primeiras variáveis canônicas explicaram 89,76\% da variação total contida no conjunto de dados originais. Correa et al. (2020), em estudo sobre diversidade genética, obteve resultados onde as duas primeiras variáveis canônicas explicaram $81,77 \%$ da variação total contida no conjunto de dados originais. Desta forma, de acordo com Cruz et al. (2014), todos os trabalhos permitem que exista uma correta interpretação da variabilidade entre os genótipos, uma vez que as duas primeiras variáveis canônicas explicaram no mínimo $80 \%$ da variação total contida no conjunto de dados originais.

O dendrograma (Figura 2) dividiu os genótipos de feijão roxo em quatro grupos. O primeiro grupo é constituído pelos genótipos CNFRx 16340 e CNFRx 16353, o segundo grupo formado por CNFR16932 e BRSCNFRx15595. O terceiro grupo constituído pelos genótipos CNFR17014, CNFR16998, BRSMG TESOURO, CNFRx16360. E o último grupo formado pelos genótipos CNFR16997 e CNFRx16352.

Figura 2. Dendrograma representativo para dez genótipos de feijão roxo, obtido pelo método de distância euclidiana, agrupamento hierárquico de Ward.

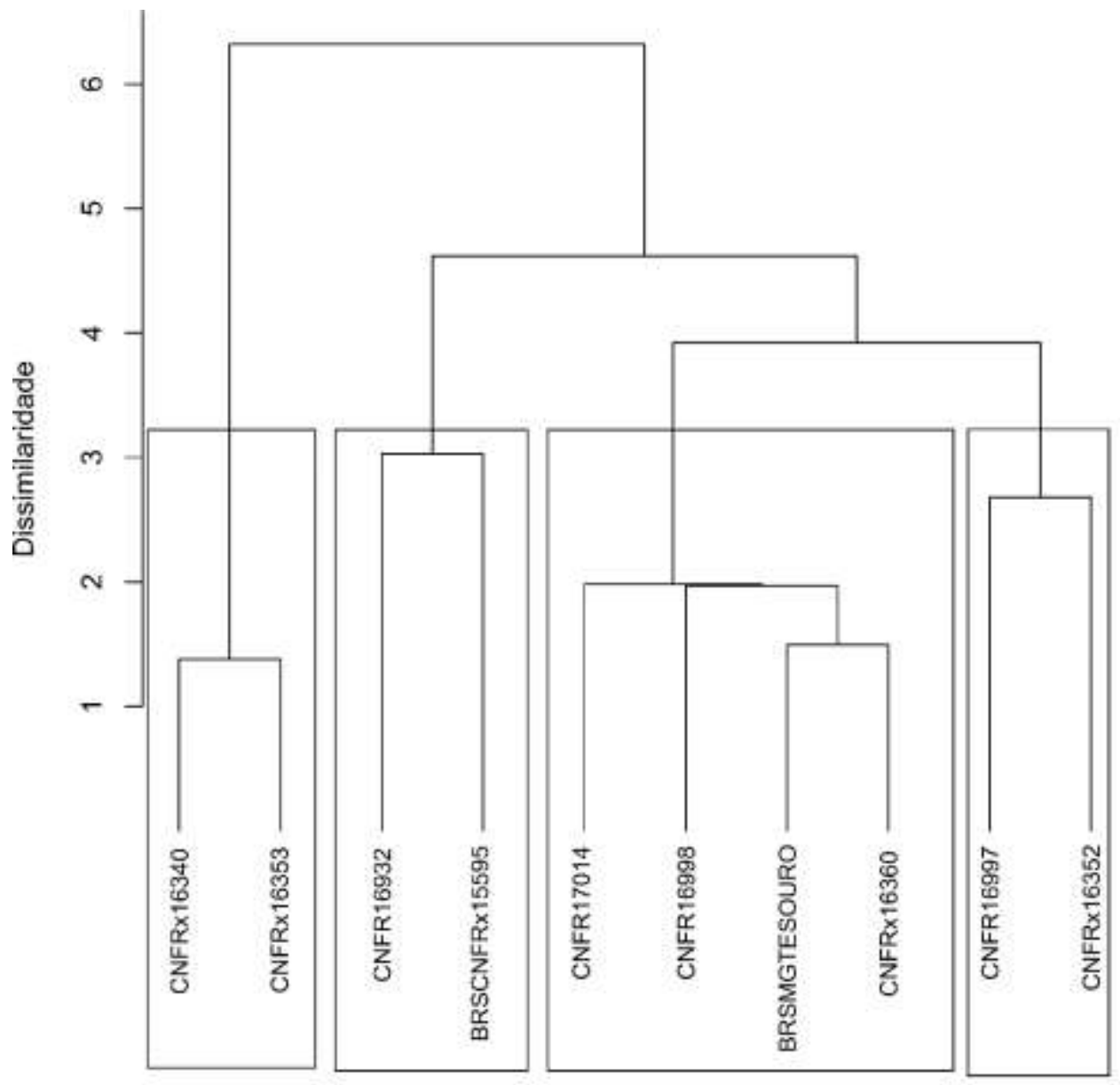

Fonte: Autores.

Das mudanças entre as variáveis analisadas, aquela de maior influência, consequentemente, de mais intensa contribuição para a separação dos grupos foi a produtividade, seguido da massa de cem grãos.

Gonçalves e Lima (2021) relatam que a formação de grupos distintos nessas análises, podem inferir que as linhagens selecionadas em cada grupo possuem os mesmos ancestrais em comum. 


\section{Conclusão}

As variáveis Massa de cem grãos e Produtividade apresentaram diferenças significativas entres os genótipos.

Para a Massa de cem grãos os genótipos BRSCNFRx15595, CNFRx16353, CNFRx 16340, CNFRX 16360 e CNFRx 16352, se destacaram.

Quanto a Produtividade os genótipos CNFRx 16353, CNFRx 16340 e CNFR 16932 foram os que apresentaram as maiores médias.

Nas análises canônicas, os genótipos CNFRx 16340, CNFRx 16353 e BRSCNFRx15595 tiveram destaque para as variáveis número de grãos por vagem, massa de cem grãos e produtividade.

A produtividade foi a variável que apresentou maior influência, consequentemente, de mais intensa contribuição para a separação dos grupos na análise de agrupamento.

\section{Referências}

Bhering, L. L. (2017). Rbio: Uma ferramenta de análise biométrica e estatística usando a plataforma R. Crop Breeding and Applied Biotechnology, 17, 187190 .

Carbonell, S. A. M., Chiorato, A. F., Bezerra, L. M. C., Gonçalves, J. G. R., Silva, D. A. D., Esteves, J. A. de F., Reis, L. L. B., Carvalho, C. R. L., Barros, V. L. N. P., Freitas, R. S., Ticelli, M., \& Gallo, PB (2020). IAC Nuance and IAC Tigre: common bean cultivars for special markets. Crop Breeding and Applied Biotechnology, 20(3). 10.1590/1984-70332020v20n3c39.

CONAB. Companhia Nacional de Abastecimento. (2020). Informações Agropecuárias. Obtido em: http:/www.conab.gov.br/info-agro/download.

Correa, V. R. S., de Oliveira, T. C., de Oliveira, A. J., Barelli, M. A. A., da Silva, V. P., Galbiati, C., \& Poletine, J. P. (2020). Dissimilaridade fenotípica em genótipos de girassol. Research, Society and Development, 9(11). 10.33448/rsd-v9i11.9814.

Chiorato, A. F., Reis, L. L. B., Capanema, L. M., \& Carbonell, S. A. M. (2018). Visão global sobre cultivares de melhoramento de feijão. Em Rocio CamposVega (Org.) Phaseolus vulgaris: cultivares, produção e usos. Nova Ciência Publishers.

Cruz, C. D., Carneiro, P. C. S., \& Regazzi, A. J. (2014). Modelos Biométricos Aplicados ao Melhoramento Genético. Editora UFV.

Cruz, C. D. (2013). Genes: a software package for analysis in experimental statistics and quantitative genetics. Acta Scientiarum. Agronomy, 35(3), 271-276. 10.4025/actasciagron.v35i3.21251.

Gonçalves, Z. S., \& Lima, L. K. S. (2021). Desempenho agronômico e diversidade genética de linhagens de feijão-caupi nas condições do Recôncavo da Bahia. Journal of Biotechnology and Biodiversity, 9(3), 285-294. 10.20873/jbb.uft.cemaf.v9n3.goncalves.

Moraes, E. D. S., \& Menelau, A. S. (2017). Análise do mercado de feijão comum. Revista de Política Agrícola, 26(1), 81-92. https://seer.sede.embrapa.br/index.php/RPA/article/view/1245/pdf.

Melo, P. H. W. (2017). Avaliação de genótipos de feijoeiro comum do grupo preto precoce no inverno, em Uberlândia Minas Gerais. Universidade Federal de Uberlândia. https://repositorio.ufu.br/handle/123456789/20842.

Ponce, M. C. R. (2017). Comportamento agronômico de genótipos de feijoeiro comum, do grupo preto, no período de inverno, em Uberlândia-MG. Universidade Federal de Uberlândia. https://repositorio.ufu.br/handle/123456789/20646.

Sulzbacher, L. J., Da Silva, V. P., Zago, B. W., \& Corrêa, C. L., Duarte, A. V. M., Barelli, M. A. A. (2017). Análise da divergência genética através de caracteres agronômicos em genótipos de feijão comum. Revista Espacios, 38(23). Obtido em: https://www.revistaespacios.com/a17v38n23/a17v38n23p26.pdf.

Schmitz, H., Ludwig, R., \& Mambrin, R. (2020). Caracterização morfoagronômica de feijões de grãos especiais. Enciclopédia biosfera, 17(34). http://www.conhecer.org.br/enciclop/2020D/caracterizacao.pdf. 